\title{
Two-year study of the causes of postperinatal deaths classified in terms of preventability
}

\author{
ELIZABETH M TAYLOR AND JOHN L EMERY \\ Wolfson Unit, Department of Paediatrics, University of Sheffield
}

SUMmARY A detailed pathological and psychosocial study was made of all postperinatal (8 days2 years) deaths in Sheffield during a 2-year period. The cause of death was classified from the point of view of possible prevention. Of the total of 65 deaths, 35 were unpreventable after the perinatal period, but 9 might have been preventable before birth. Of the 30 other deaths, 20 had evidence of possible treatable disease, and for the majority of these adverse social factors could be identified. Proved non-accidental injury occurred in 2 children and in 3 others there was a high degree of suspicion of 'gentle battering'. Only in 4 children was death unexplained and this apparently represents the local true unexplained cot death rate of $0 \cdot 16 / 1000$ births.

Confidential enquiries into infant deaths have been carried out in Sheffield since 1973. This earlier enquiry showed that at least one-quarter of the babies dying unexpectedly at home were suffering from recognisable disease. ${ }^{1}$ A study of these infants compared with age and admission matched controls suggested that the symptomatology of the children dying at home did not differ from the symptomatology of those who were successfully treated. ${ }^{2}$ In $1976,{ }^{3}$ we classified infant deaths as follows: (a) Deaths from congenital anomalies, perinatal causes, tumours, and hereditary degenerative disease.

(b) Deaths from potentially treatable conditions.

(c) Deaths during the course of a minor illness.

(d) Deaths with no evidence of terminal illness. We concluded that if the deaths in groups (b) and (c) could be eliminated, the infant mortality rates in England and Wales would be similar to those in Holland and Sweden.

In the present paper the earlier classification of infant deaths is developed to identify more accurately areas in which preventive action could be taken.

From 1976 to 1979 , confidential enquiries into infant deaths in Sheffield continued to be made in the DHSS Postneonatal Multicentre Study. After March 1979 it was decided to continue to monitor infant deaths in Sheffield, but on a long-term basis rather than as a short-term research project. It was also decided to include an in-depth psychosocial aspect in an attempt to determine underlying causes of inadequate health care. The results of the first two years are presented here.

Materials and method

Deaths in the age group 8 days to 2 years were studied during a 2-year period-1 April 1979 to 31 March 1981. Any infant whose parents' place of residence at the time of his death was in the area administered by the Sheffield Area Health Authority was included. Infants were not excluded from the study if the place of birth or site of death was outside the area. The population of the area is about half a million and there are approximately 6000 births each year. Notification of deaths came from the hospitals, or, in the case of children dying outside hospital, from mortuary attendants. Notification of deaths occurring outside the area was from the Registrar's weekly returns.

Full data were obtained in every case except for 2 deaths from non-accidental injury; for these data were incomplete because both were subjudice for many months after the deaths. Information was abstracted from obstetric records in all cases, and from paediatric and casualty records if the child had been seen by a paediatrician or in a casualty department. Questionnaires were completed on all cases by a health visitor, and in all but 3 cases by the family doctor. Written reports were obtained from the midwife on all babies still being visited at home by the midwifery services at the time of death, and from social workers if they had been involved with the family. A home visit was made about 4 weeks after every death except for the two from non-accidental injury and one death from congenital heart disease. The mother of the last infant leit Sheffield immediately after her infant's death. Most home visits were made by one of us; a few were made by the health visitor. The home visit generally lasted about 2 hours. The prime purpose of the visit was data collection and an extensive questionnaire was used. Time was also 
given to bereavement counselling. Necropsy reports were obtained on all cases except the 18 for which no post-mortem examination had been made. All the unexpected deaths had a full paediatric necropsy with relevant investigations. Most of these were carried out by one of us (J L E) and the rest by Dr S Variend.

A case conference was held on every case. If the baby had died at home the conference was held either in the family doctor's surgery or at a place of his choice and at a time to suit him. The family doctor was present at such conferences on all children who died at home except one. In that case the family were not registered with any GP. Case conferences on some hospital deaths were held in the GP's surgery. If the family doctor had not been involved, the conference was held in the hospital. Paediatricians attended conferences both in the hospital and in the family doctor's surgery. At the conference all data, including the necropsy report, were discussed making it possible for the primary health care team to plan the future health care of the family. At the conference the participants were asked to decide if the death had been 'probably inevitable' or 'possibly preventable', and if the latter, at which stage possibly successful intervention might have been made. Each death was then classified in an attempt to identify groups for which preventable action might have been taken. This classification is an extension of one previously developed, ${ }^{3}$ and is set out in Table 1.

\section{Results}

In the 2-year period of our present study there were 12111 births. Sixty-five babies died between ages

\section{Table 1 Classification of infant deaths}

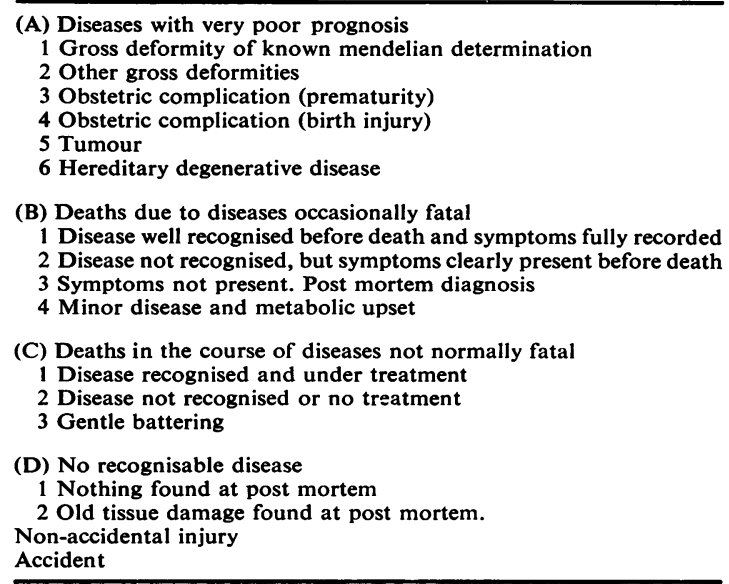

8 days and 2 years. Post-mortem examinations were performed on 47 infants, 33 being paediatric necropsies with full investigations. Table 2 gives the total number of children dying according to each category and place of death.

Category A. Thirty-five (54\%) of the total of 65 deaths came into this category - that is deaths from conditions with poor prognosis. Three of these deaths were from obviously genetically determined conditions such as familial microcephaly. Twentyone were from the other gross deformities-such as congenital heart defects and neural tube defects. There were 9 children who were potentially anatomically normal; 7 of whom were grossly preterm, 2 of whom died as a result of birth injury. There was one death from tumour and one from an hereditary degenerative condition (Werdnig Hoffman disease). If deaths due to late obstetric factors are excluded, the number of probably inevitable deaths is $26(39 \%)$.

Category B. In this category, there were $20(31 \%)$ deaths. Of the 5 children dying in hospital, 2 died with the Waterhouse-Friedrickson syndrome and 3 with acute infections of the respiratory tract. There were 15 deaths at home. Eight of these children had symptoms before death which could have merited hospital admission. These symptoms had been inadequately identified and inadequately responded to. These children died with the following conditions: pneumonia $(n=2)$; tracheobronchitis $(n=2)$; Haemophilus influenzae infection $(\mathrm{n}=2)$, one having a meningitis and the other a generalised infection; gastroenteritis $(n=1)$; respiratory tract infection associated with atopy $(n=1)$.

\section{Examples of deaths in category $B$}

B1 Hospital death. This baby died at age 8 weeks with cerebral oedema and coning due to severe viral bronchitis. She was born at 31 weeks' gestation and suffered from respiratory distress during the first week of life. She regained her birthweight and was discharged home at 16 days. At 6 weeks she developed a respiratory infection and was readmitted. For the first 2 days after admission she did not seem to be seriously ill. She then developed breathing problems and her condition deteriorated rapidly requiring ventilation from the second day of admission. Her condition continued to deteriorate. Respiratory syncitial virus was isolated from the nasopharynx. On the seventh day of ventilation, all tests indicated brain death and ventilation was stopped. 


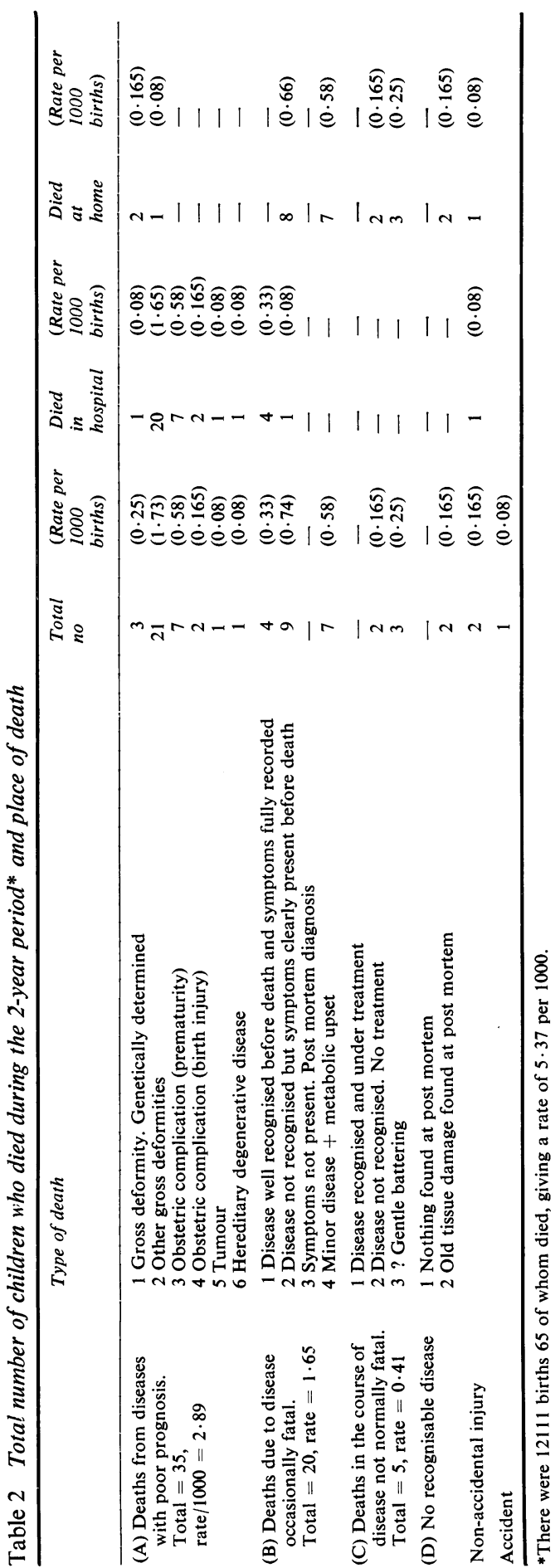

B2 Hospital death. This baby died at age 5 months. $\mathrm{He}$ had been admitted to hospital, mainly because his parents were anxious, during the evening before his death with a 4-day history of upper respiratory tract infection. On admission he was a cross, hungry baby with mild pyrexia. Ears and throat were normal. There were coarse crepitations and rhonchi in all areas but the percussion note was resonant. He was put in a steam tent and investigations were started. He was seen by the ward sister at 0400 hours, when his condition appeared good. When she passed the tent again 2 or 3 minutes later he was apparently dead. The cardiac alert team was called but resuscitation was unsuccessful. The certified cause of death was 'acute infection of the respiratory tractunexpected death in infancy'. After full paediatric necropsy, the final cause of death was $H$. influenzae, bronchitis, and pneumonia.

B2 Home death. This baby died at age 13 months. She developed a respiratory tract infection 4 days before her death and was visited by the GP 2 days before her death. She subsequently became increasingly lethargic and lapsed into coma. Her parents thought that her deep sleep was a sign that she was recovering and did not recall their GP. Death was due to Haemophilus meningitis.

B2 Home death. This baby, one of twins, died at age 4 months. The mother who was 19 had 4 children all under age 3 years. When the twins were 3 months old the mother became depressed. At 4 months both twins became seriously ill, one with pneumonia and the other with gastroenteritis, both probably viral in origin. The mother either did not recognise their illness or was unable to respond to it. One twin died at home; the other was virtually moribund on admission to hospital but eventually recovered. The death was registered as 'unexpected death in infancy'. Full necropsy showed pneumonia, wasting, and a fractured rib. Much later the mother admitted to hitting and squeezing both twins over a long period.

B4 Home death. This baby died at age 14 weeks. She was a thriving, fast growing, bottle-fed baby. A week before her death the father returned home on a short leave from Borstal training. The parents noticed no terminal illness. On the day of the child's death, the mother accompanied the father to the railway station at the end of his leave. The baby was left in the care of a friend. Shortly after her return to the house the mother found her baby dead in her cot. Post mortem showed histological evidence of minor gastrointestinal disorder, a hyperelectrolytaemia of $338 \mathrm{mmol} / \mathrm{kg}$, with a urea level of $10.8 \mathrm{mmol} / \mathrm{l}$. At the case conference it was concluded that symptoms 
of the baby's illness had not been noticed by the parents because of the state of crisis engendered by the father's imminent return to Borstal. Death was registered as 'unexpected death in infancy'.

B4 Home death. This baby died at age 4 months. The mother was a young unmarried girl living alone at the time who was in a state of severe emotional distress, her boyfriend having recently left her. The mother noticed no terminal illness, finding her baby dead after a period of sleep of about 12 hours. Necropsy showed frank bilateral otitis media and slight mastoiditis, severe dehydration, and an osmolality of $331 \mathrm{mmol} / \mathrm{kg}$. Death was registered as 'unexpected death in infancy'.

Category C. In this study there were no deaths in the category $\mathrm{C} 1$.

In category $\mathrm{C} 2$ are children who would usually come under the heading of true cot deaths, but neither child was in any sense normal nor were the circumstances normal, and each child showed evidence of some acute disease.

One who died at home at 7 months came from a well-known local 'problem family'. The family had been using the baby as a means of trying to have the family rehoused. The investigation of this child's death was unsatisfactory. The baby was found excessively clothed; the parents had been complaining that the house was cold and damp. The house was a centrally heated, modern council flat. Unfortunately, the temperature of the child was not taken at the time he was found. Post mortem showed many minor pathological features including bilateral otitis media and acute infection of the respiratory tract. There were many inconsistencies in the history given by the mother.

The other child in this category had an unusual history. The mother went to America to have her baby. They returned when the baby was aged 5 months and when he died 2 months later neither the family doctor nor the health visitor knew of her return to the city nor did they know of the child's existence. This baby died during the course of a minor illness. At the home visit after this child's death, the American mother explained that she had not used the health care services in this country because they were unfamiliar to her and she did not understand them.

\section{C3 Gentle battering}

Three babies were placed in this category. Deaths were placed in this category only after extensive discussion at the case conference and with the agreement of all those present.

Example. A baby who died at age 3 months. There was a history of a previous cot death. The mother had a history of psychotic illness and of severe recurrent back pain for which she had had an unsuccessful laminectomy. There was a history of marital problems and the parents had been recently separated. Many different versions of the terminal event were presented by the parents who both appeared to create fantasies about their child. Necropsy showed upper respiratory tract infection only, with no evidence of severe metabolic disturbance. At the case conference it became apparent that the family doctor, the health visitor, the pathologist, and the doctor who had visited the parents for the purpose of this study, had all independently developed grave anxieties about the nature of the events that had preceded this child's death. Death was registered as 'unexpected death in infancy'.

Category D2. The two children in this category constituted what may be termed true cot deaths. The first of these children came from middle-class, prosperous parents, and was fully breast fed. She was found moribund in the back of their car at the end of a 5-minute journey. The only possibility of abnormality found at necropsy was evidence of a small area of tracheal dysplasia at the level of the carina. The other child was from a completely different social background. The husband was an unemployed labourer. The baby was very well cared for and was fully breast fed. The necropsy found no evidence of terminal disease. The only lesion found was vocal cord necrosis, the significance of which we are not yet able to assess.

The two non-accidental injuries were both court convictions.

The one accidental death occurred when the mother slipped and let go of the pram which ran under the wheels of an oncoming lorry. At the time of the accident the mother was suffering from the effects of a neoplastic condition, for which she attended hospital 3 weeks later giving a history of symptoms which preceded her child's death. There were also family and marital problems.

\section{Discussion}

Since infant deaths began to be monitored in Sheffield in 1973, the incidence and pattern of deaths have changed. Before 1973, the combined incidence of deaths from infection, accident, and cot death was above the national average. By 1980 , it had fallen to well below the national average ( $R$ G Carpenter et al, Unpublished data) (Figure).

The pattern has also changed. Before 1973, fewer than half of the deaths occurred in hospital and about one-third were thought to be inevitable. ${ }^{4} \mathrm{By}$ 1980, inevitable deaths constituted more than half 


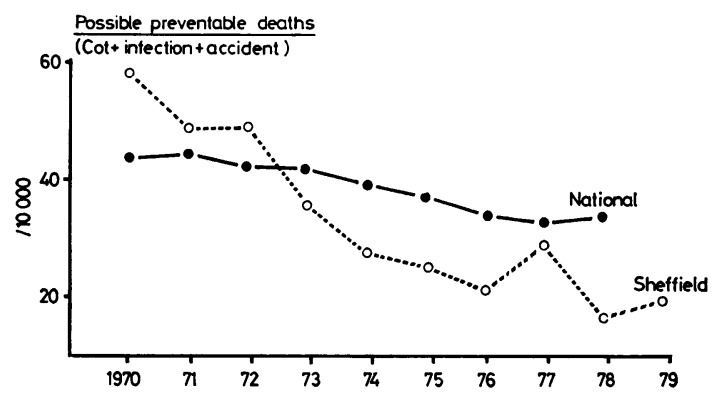

Figure Possibly preventable deaths (deaths certified as acute infections, cot deaths, and accidental deaths) per 10000 births.

(Rates for England and Wales (OPCS) and the Sheffield Area)

the deaths although the total number was smaller. The greatest change was in the reduction in the number of unexpected deaths at home in our classification B (possibly treatable).

This investigation is a development of previous work. A much greater depth of information has been made available by holding the final case conference in the family doctor's surgery and much more psychosocial information was obtained.

In category $A$ were 35 of the total of 65 deathsthat is more than half of all infant deaths had determining factors present before the 8th day of life. These can be divided into two groups. Those with gross anatomical deformities either genetically determined or otherwise, which constituted about two-thirds of the total deaths in this category. Any preventive measures aimed at this group will involve work in the field of teratogenesis, genetic counselling, or fetal diagnosis. The other group of children $(n=9)$ were apparently genetically normal but had been so damaged by disease related to late intrauterine life or to labour that they later died. These form a group which requires a special investigation on its own, related to antenatal and intrapartum factors. This group appears locally to be increasing in number associated with increase in perinatal care. It is obvious that any future discussion of perinatal mortality must include some babies dying during the first year of life.

Our category B is useful principally because it is the one group in which conventional paediatric therapy has an obvious role; its importance is well recognised. ${ }^{45}$ There are many factors active in this group of deaths. The majority of these babies presented as unexpected deaths at home and they constituted 15 of the total 25 home deaths. Possibly treatable factors were present in all these children and these deaths must be regarded as theoretically the most easily preventable. This is the group in which there has already been the greatest diminution in deaths locally. ${ }^{6}$

There were far fewer deaths in categories $C$ and $D$. In category $C$ there were 5 deaths. Although there was some evidence that acute terminal disease was present in 2 of them, it was not thought to be sufficient to explain death and we could find no remediable factor. In the other 3 children, a minor disease was present but other evidence enabled us to give an explanation of death. There were only 2 children in category $D$. After the most detailed pathological study available to us we were unable to explain death or find any evidence of recent illness. These constitute true mystery deaths. There were thus only 4 children for whom we have no idea about the cause of death-that is for whom the expression 'true unexplained cot death' could be legitimately applied - and in only 2 of these was there no evidence of acute disease.

In Sheffield it is the practice to use a double registration of death ${ }^{7}$ so that a disease process may be identified and the death also described as unexpected death in infancy (Table 3). There were 19 deaths in Sheffield during this 2-year period that came within the Registrar General's statistics of cot deaths. This gives a rate of 1.56 per 1000 births which, although lower than the national average, stresses the very great importance of this category of child death. If the unexpected deaths in Sheffield are regarded from the point of view of unexplained unexpected deaths, there are either 7 or 4 depending on whether the interpretation is made purely on post mortem findings or on a complete study including the psychosocial background. These give cot death rates of 0.58 per thousand or 0.165 per thousand births. The importance of these figures lies in the fact that the latter figure represents our completely unexplained cot death rate. These rates are very close to or even lower than the cot death rates in such countries as Finland and Sweden. We are thus able to identify a rate for what may be defined as currently completely unexplained deaths,

Table 3 Distribution of deaths certified as unexpected death in infancy

\begin{tabular}{|c|c|c|c|c|c|}
\hline $\begin{array}{l}\text { Classification } \\
\text { of death }\end{array}$ & Total & $\begin{array}{l}\text { Certified as } \\
\text { 'unexpected } \\
\text { death in } \\
\text { infancy' }\end{array}$ & $\begin{array}{l}\text { Died in } \\
\text { hospital }\end{array}$ & $\begin{array}{l}\text { Died at } \\
\text { home }\end{array}$ & \\
\hline (A) & 35 & 0 & 32 & 3 & \\
\hline $\begin{array}{l}\text { (B1) } \\
\text { (B2) } \\
\text { (B4) }\end{array}$ & $\begin{array}{l}4 \\
9 \\
7\end{array}$ & $\begin{array}{l}0 \\
7 \\
5\end{array}$ & $\begin{array}{l}4 \\
1 \\
0\end{array}$ & $\begin{array}{l}0 \\
8 \\
7\end{array}$ & \\
\hline $\begin{array}{l}\text { (C3) } \\
\text { (C2) }\end{array}$ & $\begin{array}{l}3 \\
2\end{array}$ & $\begin{array}{l}3 \\
2\end{array}$ & $\begin{array}{l}0 \\
0\end{array}$ & $\begin{array}{l}3 \\
27\end{array}$ & Unexplained \\
\hline (D2) & 2 & 2 & 0 & $2\}$ & deaths \\
\hline
\end{tabular}


remembering that all of the babies who are diagnosed as cot deaths even in the Scandinavian countries are not necessarily completely unexplained ( $G$ Von Sydow, 1970, personal communication).

Non-accidental injury is now a well-known condition. The group that we call gently battered (which includes smothering) is numerically equal to or greater than the non-accidental injury group. These cases are distinguished from the unexplained unexpected deaths only by a joint social and pathological study. One of the reasons why we are content to continue to include them in the broad group of cot deaths is that it enables us to work with the parents and other subsequent children. In this group the holding of a case conference in the GP's surgery is particularly important. Confidential information can be shared and plans made for the future health care of the family.

The results of this study indicate the need for a flexible approach to the problem of child deaths, and hence for bringing health care to all children. We agree with Alberman on the need for several different approaches to the provision of health care in the perinatal period. ${ }^{8}$ We have shown that 9 of the deaths in overtly normal infants had their origins in the pre- or perinatal period. In attempting to identify zones of activity for the prevention of postperinatal death, a study of the late antepartum period is of equal importance to that of the postperinatal period. A pilot study suggests to us that the psychosocial problems in both groups are remarkably similar.

\section{References}

1 Emery J L. Confidential Report to DHSS on post perinatal deaths in Sheffield and Rotherham. 1975.

2 McWeeny P M, Emery J L. Unexpected post-neonatal deaths (cot deaths) due to recognizable disease. Arch Dis Child 1975; 50: 191-6.

3 Emery J L. Postneonatal mortality in Sheffield. Proc Roy Soc Med 1976; 69: 338-40.

4 Richards I D G, McIntosh H T. Confidential inquiry into 226 consecutive infant deaths. Arch Dis Child 1972; 47: 697-706.

5 Morrison S S. Sudden and unexpected death in early life. JAMA 1960; 173: 1199-204.

6 Emery J L. Cot deaths. The current situation and the role of the health visitor today. Health Visitor 1981; 54: 318-20.

7 Emery J L, Weatherall J A C. Letter: Certification of cot death. $\mathrm{Br}$ Med J 1972; iv: 669.

8 Alberman E. Perinatal mortality rates. Br J Hosp Med $1978 ; 20$ : 439-43.

Correspondence to Dr E M Taylor, Wolfson Unit, 312 Fulwood Road, Sheffield S10 3BR.

Received 10 May 1982 